\title{
Perception of social advertising on a value- semantic level by students of humanitarian orientations
}

\author{
Anna Kukuliar, Anastasia Grishina ${ }^{*}$, Olga Chinarova and Alisa Achina \\ Don State Technical University, Faculty "Psychology, Pedagogy and Defectology", \\ 344000 Rostov-on-Don, Russian Federation
}

\begin{abstract}
This article reflects the results of an empirical study of the value-semantic features of social advertising perception among a group of students (male and female). In total, 200 students took part in the study. In the framework of the study, the following methods were applied: "Value Orientations" (A.Ya. Rokich), "SJO" (D.A. Leontiev), "Determination of Personality Orientation" (B. Bass), "Psychosemantic Differential" methodology, questionnaire for determination of attitude to social advertising. The results of this study reveal the presence of the following relationships: 1) Features of the personality's value-semantic sphere significantly affect the perception of social advertising by young people. 2) The images on which social advertising is centered as on the values conveyed by society and the state are transformed in the mind of the perceiver, depending on his value and personal orientation. 3 ) It is possible to identify some specific features of the visual and verbal influence of social advertising on young people.
\end{abstract}

\section{Introduction}

Psychological and social studies of recent years indicate a lack of attention to the young generation that is entering into life, which entails the formation of a powerful factor in the destabilization of society.

Communicating during the lecture classes with students of various faculties and courses, it can be noted that most of them have not formed, lost or destroyed such traditional moral features as altruism, honesty, dedication, justice, good faith, faith in goodness, romanticism, readiness for achievement, as well as the desire for truth, the search for the ideal, for the positive realization of not only personal, but also socially significant interests and goals. At the moment, students have an interest in life and death issues, general humanitarian problems and their social status, paradoxically combined with an underdeveloped ability to objectively evaluate specific actions, to self-control behavior (L.I. Bozhovich, S.A. Gaponova, Yu. B. Mozhginsky, A.A. Ushanova, D.I. Feldstein and others). As a result, the problem of research seems to us in the impoverishment of the value understanding of the world by man. From what there is a

* Corresponding author: avgrishina.sfedu@gmail.com 
patterned representation of life among young people, unconditional, blind following the proposed invented world, expressed in demonstration and imposing from the immediate means of subsistence to luxurious, prestigious attributes [7].

We consider it relevant and timely to present the results of an empirical study on the psychological characteristics of the social advertising perception by 1-2 year students at the value-semantic level, since nowadays, reflections of acute social problems that are of great importance in modern society have become increasingly used in advertising. Every year, social advertising takes its direction in achieving solutions to social relations and problems in society, trying to send people to a healthy lifestyle, to protect and support vulnerable people, to fight poverty, crime, corruption, environmental pollution and many other important social factors. Also, social advertising can be considered as a way of disseminating spiritual, aesthetic, moral and social values. The main objective of this advertisement is not only a social problems reflection, but also a call to solve them using modern communication channels and advertising.

We note the fact that I.V. Abakumova in her works showed that the meaningformation of the youth personality is represented by the interaction that generates individualized meanings, turned inside the subject of knowledge, i.e. through the meaning of one's own activity, actions and introspection. A.G. Asmolov in his scientific works notes that the manifestation of an individual's personality in situations of personal choice is the use of social stereotypes as a means of mastering one's behavior. Thus, we approached the research problem of interest to us, namely, to social advertising as a translator of personal values acceptable within the framework of modern youth society $[1,2,3,4,5]$.

\section{Materials and methods}

In the course of an empirical study, we diagnosed students of 1-2 courses at the age of 18-20 years in the amount of 200 people (100 men and 100 women) to study the characteristics of social advertising perception.

We have put forward the following hypotheses: 1) Features of the value-semantic sphere of personality significantly affect the perception of social advertising by young people. 2) The images on which social advertising is centered as on the values conveyed by society and the state are transformed in the mind of the perceiver, depending on his value orientations and personal orientation. 3) It is possible to identify some specific features of the visual and verbal influence of social advertising on young people.

As part of an empirical study, we applied the following methods: "Value orientations" (A.Ya. Rokich), "Test of meaning-life orientations" (D.A. Leontiev), "Determination of personality orientation" (B. Bass), "Psychosemantic differential", the authors' questionnaire on determining the attitude to social advertising.

The semantic content of social advertising, which we consider as an image, a thought form, an imprint of the students' personality life meaning, is further manifested in the activity of their semantic sphere, in its enrichment. With the development of general psychology, with the identification of a new theory of meaning and meaning formation, the theory of perception accumulated various theories and acquired new additional information. The perception of social advertising, despite the laconicism of the meanings and images embedded in the advertising product, has a complex multilevel structure, which over time basically does not change (A.V. Kostina, E.F. Makarevich, O.I. Karpukhin). Based on the fact that the product of social advertising contains a vivid, concise, accessible artistic image for the consumer, such methodological developments as the study of the process of fine art in connection with the problem of "feedbacks" (N.N. Volkov); the ability to perceive reality in the 
categories of creativity (S.M. Daniel); the translation of any modality images into visual schemes (the tendency of visualization of sensory experience) and the development of the signifying function of speech "verbalization of all life experience" (B. G. Ananyev); unity forming consciousness: meanings, sensory fabric and personal meaning (A.N. Leontiev); perception as an aesthetic experience by A. Maslow and others allowed us to select various types of social advertising from the point of view of the artistic image originality and content; integrity of perception; speed, brightness and clarity of memorability, productivity, versatility for our empirical research $[6,8,9,10,11,12,13]$.

As a result of presenting cards with various social advertising images and according to the list of questions from the questionnaire, we can conclude that there are differences in determining the attitude to social advertising among men and women in two main indicators: 1. "pay attention to social advertising" and 2. " the text part of social advertising carries an information load. "So, in general, young men pay more attention to social advertising (53\%), women - $22 \%$. The indicator "the textual part in social advertising carries an information load" showed the value for men - $23 \%$, for women - $12 \%$, which allows us to talk about the difference in psychological characteristics in the perception of young men and women.

Analysis of the questions asked in the author's questionnaire seems to be interesting. Consider the question "What kind of advertising (in content) attracts your attention?" Such areas of social advertising as a moral, healthy lifestyle, life safety, any other,- were proposed.

Female students set such priorities as moral (28\%), any (28\%), life safety (25\%), healthy lifestyles (19). Young male students set such priorities: moral (0\%), life safety (28\%), healthy lifestyles (31), any (41\%).

Considering the following question "What kind of advertising (in appearance) attracts your attention?" such appearances (styles) of social advertising as "bright and colorful", concise, photo, cartoon, font were suggested. Female students set their priorities as follows: "bright and colorful" (37\%), "photo" (31\%), "cartoon" (26\%), "concise" $(6 \%)$, "font" $(0 \%)$. Young male students set their priorities as follows: "font" (37\%), "photo" (25\%), "bright and colorful" (19\%), "concise" (16\%), "cartoonish" $(3 \%)$.

Thus, we can conclude that there are differences in the specifics of perception of social advertising for male and female students. On the basis of which it can be judged that when creating social advertising it is necessary to combine "effective" images designed for both men and women, or to launch different external types of social advertising with its own specific orientation.

Consider the following question: "Which character attracts your attention?" Parameters - "young man", "girl”, "child", "zoomorphic character", "fairy-tale character", "any",- female students set their priorities as follows: "child" (32\%), "fairytale character" (21\%), "zoomorphic character" (19\%), "girl” (15\%), "young man" (11\% ) Young male students spoke like this: "girl" (69\%), "fairy-tale character" (19\%), "child" (5\%), "zoomorphic character" (5\%), "young man" (0\%).

The results obtained also allow us to judge the presence of specific features in the choice of the preferred main character among male and female respondents, but we can speak equally about the influence of the age criterion that affects the choice.

According to the "Psychosemantic Differential" methodology (in the author's version), the following results were obtained.

In this technique, various types of social advertising were proposed, and the task was to choose from paired opposite statements, which, in your opinion, corresponds to your impression of a particular social advertising picture. Pictures offered 10 pieces. The average indicators revealed the highest frequency of the criterion: 
Among the group of young women: 1) Necessary - unnecessary (41.89), 2) Attractive - not attractive (41.56), 3) Important - unimportant (40.59).

Among the group of young men: 1) Significant - not significant (34.87), 2) Important - unimportant (34.62), 3) Necessary - unnecessary (33.97).

Analyzing the data obtained, it can be concluded that the "important - unimportant", "necessary - unnecessary" serve as the matching criteria in both samples, and generally reflect the perceptions of young people in the context of social advertising importance and value.

The results by the method of "Determining the orientation of the personality" by B. Bassa showed that female students are focused on the parameter "focus on business" ( $t$ $=2.34$ at $p=0.031$ ). Perhaps this is due to the fact that they study most carefully and for them it is an important stage in life. Young male students showed high results in the "self-orientation" parameter $(\mathrm{t}=2.65$ at $\mathrm{p}=0.039)$, which manifests itself in a certain degree of authority, a tendency to rivalry, as well as anxiety and irritability. Perhaps this is due to the fact that young men now need to think about more distant prospects in their lives. Among male and female respondents, almost equal and rather high indicators reached the value on the scale "focus on communication" (men - 32 points, women - 33 points) $\mathrm{t}=2.39$ at $\mathrm{p} 0.028$. The results obtained testify to the desire of respondent groups to maintain relationships with people under any conditions, they are focused on joint activities and social approval, can be dependent on the group, they also have a need for emotional relationships and affection for people.

As a result of a diagnostic study on the "Test of meaning-life orientations" by D.A. Leontiev received the following data, which are presented below in Table 1.

It can be seen from the data presented that the overall meaningfulness of life is higher for young women than for young men, which indicates the fact that this particular group of students reflects more on the characteristics of their own lives and the future. Perhaps this is due to the fact that women understand better what they want from life and in what time frame.

Table 1. Results of "Test of meaning-life orientations" by D.A. Leontiev

\begin{tabular}{|c|c|c|c|c|c|c|}
\hline & Aims & Process & Result & $\begin{array}{c}\text { Locus of } \\
\text { control-I }\end{array}$ & $\begin{array}{c}\text { Locus of } \\
\text { control - } \\
\text { Life }\end{array}$ & $\begin{array}{c}\text { General } \\
\text { indicator of } \\
\text { life } \\
\text { meaningful } \\
\text { ness }\end{array}$ \\
\hline Young men & 27,72 & 29,16 & 21,5 & 17,1 & 25,25 & 120,63 \\
\hline $\begin{array}{c}\text { Young } \\
\text { women }\end{array}$ & 31,31 & 28,78 & 25,56 & 14,18 & 26,1 & 125,93 \\
\hline $\begin{array}{c}\text { t-test } \\
\text { Student's T- } \\
\text { Test) }\end{array}$ & 1,83 & 1,12 & 4,23 & 2,66 & 2,22 & 1,30 \\
\hline $\begin{array}{c}\text { Significance } \\
\text { level (p) }\end{array}$ & 0,038 & 0,023 & 0,001 & 0,019 & 0,029 & 0,017 \\
\hline
\end{tabular}

Summarizing the data presented, it can be said that the meaningful life strategies of young men are characterized by a tendency to control their life within the framework of the learning process, and are also aimed at obtaining higher education as the basis for further professional development.

As for the young women, their approach is based on the desire to achieve their goals. They take maximum responsibility for their future, considering only themselves 
the mistress of their own destiny. They are characterized by an adequate perception of the environment. The minimum value is attached to the selfcontrol.

Thus, as a result of the analysis, it was found that the life-meaning orientations in the female and male groups differ, but not significantly. The data presented were confirmed statistically.

Evaluating the results using the "Value Orientations" Test (M. Rokich), we can conclude that differences in terminal values (goal-values) were revealed among the female sample. In the first place are such values as: interesting work (6.4), the beauty of nature and art (4.1), love (4.8); in instrumental values (values-means) in the female sample in the first place are such values as education (5.8), cheerfulness (4.3) and strong will (4.5).

Among young men, terminal values (goal values) are dominated by honesty (6.2), strong will (5.4), and efficiency in business (5.6). In instrumental values (valuesmeans), the most common values came first - materially secure life (4.8), happy family life (4.6), the beauty of nature and art (3.9), freedom (3.7).

\section{Results}

Summarizing the data presented, we can conclude that among male and female respondents there is an individual specificity in the perception of instrumental and terminal values.

The most informative and interesting result was shown by the interpretation material on the author's questionnaire and "Test of meaning-life orientations". There is a correlation between such criteria as the existence of a goal in life, orientation to the process in life ("Test of meaning-life orientations") and focusing on the image of the child as a significant subject in life, taken from the questionnaire "What character attracts your attention?". This confirms our hypothesis that the images on which social advertising is centered as on the values, transmitted by society and the state, are transformed in the mind of the perceiver, depending on their value orientations and personal orientation.

The hypothesis "The value-semantic sphere of the personality significantly affects the perception of social advertising by young people" was confirmed in the methodology "Value Orientations" (M. Rokich) through the specifics of the distribution of terminal and instrumental values in male and female groups. In the methodology, the psychosemantic differential was proposed to determine from paired opposing statements that which, in your opinion, corresponds to your impression of a particular picture of social advertising. The average indicators for both samples of students coincide in the criteria: "important - unimportant", "necessary - unnecessary", which also reflects the confirmation of our hypothesis.

\section{Discussions}

Well, and, of course, all the empirical research in the complex gives us reason to argue that it is possible to identify some specific features of the visual and verbal impact of social advertising on young people.

Also, according to the results of the study, we propose to divide the levels of the semantic sphere of the personality of students: low - situational, medium - egocentric, high - collective.

The article was supported by the Russian Foundation for Fundamental Research (Project No. 18-29-22004 (2018) «Psychological and genetic studies of users' behavior predictors that determine the perception of Internet content of various informational orientation»). 


\section{References}

1. I.V. Abakumova, Learning and meaning: sense formation in the educational process (Publishing House of Rostov State University, Rostov-on-Don, 2002)

2. I.V. Abakumova, Meaning of didactics: a textbook for masters of pedagogy and psychology (CREDO, Moscow, 2008)

3. I.V. Abakumova, P.N. Ermakov, E.A. Makarova, Pattern and background: introjection in a heterogeneous semiotic space (CREDO, Moscow, 2007)

4. I.V. Abakumova, P.N. Ermakov, I.A. Rudakova, Didactic methods: structuralsemantic analysis: a textbook for masters of pedagogical and psychological specialtie (Southern Federal University Press, Rostov-on-Don, 2007)

5. A.G. Asmolov, Psychology of Personality. Principles of general psychological analysis (Meaning, Moscow, 2001)

6. A.B. Belyanin, Social advertising as a communicative management resource (Moscow, 2005)

7. I.Yu. Burenkov, Social advertising is a component of civil society. Information and analytical portal "Social Advertising". URL: http://www.bestreferat.ru/referat8615.html

8. J.Yu. Kara, Technologies of figurative influence: the methodology "Social distance of television content of an ideological orientation". Psychology of the formation of antiterrorist values of students of a modern university: a training manual (CREDO, Moscow, 2013)

9. P.A. Kuznetsov, Social advertisement. Theory and practice: a training manual (Unity Dana, 2012)

10. G.V. Nikolayshvili, A brief history of social advertising (Moscow, 2006)

11. G.V. Nikolayshvili, Social advertisement. Theory and practice (Aspect Press, Moscow, 2008)

12. Social advertising through the eyes of youth. URL: http://www.bibliofond.ru/view.aspx?id=554474

13. Social advertising and its role in the life of modern youth. URL: http://sibac.info/index.php 